\section{CICLOS DE ESTRANGEIRIZAÇÃO E CONCENTRAÇÃO DA TERRA NO PARAGUAI}

Lorena Izá Pereira ${ }^{1}$ Bernardo Mançano Fernandes ${ }^{2}$

RESUmo: O Paraguai possuí a maior concentração fundiária do mundo, com o índice de Gini de 0,93. Concomitantemente, 19\% do território paraguaio estava (2008) em posse de estrangeiros (CAN, 2008) e está classificado como terceiro maior exportador e sexto maior produtor de soja do globo (CAPECO, 2018). Apesar desta conjuntura atual, a concentração e estrangeirização da terra no Paraguai se configuram como processos históricos, desde o final da Guerra da Tríplice Aliança (1864-1870) e que com o passar do tempo tornam-se mais complexos, interagindo ainda mais com processos econômicos e políticos globais (ARRIGHI, 2008). Neste cenário, o objetivo deste trabalho é debater acerca do processo histórico de apropriação do território paraguaio por estrangeiros desde 1870 até o período atual, evidenciando as estratégias, papel do Estado, relações geopolíticas e impactos na estrutura fundiária do país. Entender este processo histórico é essencial para compreender as raízes da atual concentração da terra, estrangeirização do território e transformações agrárias ocorrentes no Paraguai. Para atingir este objetivo, para além de revisão bibliográfica, utilizaremos dados de diferentes agências de pesquisas e entrevistas construídas durante trabalho de campo em diferentes departamentos paraguaios entre os anos de 2015 e 2018, que nos permite refletir acerca das contradições do agronegócio e dos impactos resultantes desta apropriação de terras por estrangeiros, tais como desterritorialização de camponeses e indígenas, insegurança e perda da soberania alimentar, aumento da população em favelas e acentuação da pobreza rural e urbana, o que evidencia que os impactos desde modelo estão para além do espaço rural.

'Doutoranda em Geografia pela Universidade Estadual Paulista (UNESP), campus de Presidente Prudente; Pesquisadora do Núcleo de Estudos, Pesquisas e Projetos de Reforma Agrária (NERA); Bolsista da Fundação de Amparo à Pesquisa do Estado de São Paulo (FAPESP); E-mail: lorena.izap@gmail.com.

${ }^{2}$ Professor do Departamento de Geografia da Universidade Estadual Paulista (UNESP), campus de Presidente Prudente; Pesquisador do Núcleo de Estudos, Pesquisas e Projetos de Reforma Agrária (NERA); E-mail: mancano. fernandes@unesp.br
Palavras-chave: Estrangeirização da terra; Concentração fundiária; Disputa territorial; Geopolítica da questão agrária.

Abstract: Paraguay has the largest land concentration in the world, with the Gini index of 0.93 . Concurrently, $19 \%$ of Paraguayan territory was (2008) in the possession of foreigners (CAN, 2008) and is ranked third largest exporter and sixth largest soybean producer in the world (CAPE$\mathrm{CO}, 2018)$. In spite of this current situation, the concentration and foreignization of the land in Paraguay are configured as historical processes, since the end of the Triple Alliance War (1864-1870) and over time they become more complex, interacting even more with processes economic and political issues (ARRIGHI, 2008). In this scenario, the objective of this work is to discuss the historical process of appropriation of Paraguayan territory by foreigners from 1870 to the current period, highlighting the strategies, role of the State, geopolitical relations and impacts on the land structure of the country. Understanding this historical process is essential to understand the roots of the current concentration of land, the foreignization of the territory and the agrarian transformations that occurred in Paraguay. In order to reach this objective, in addition to a bibliographical review, we will use data from different research agencies and interviews built during field work in different Paraguayan departments between the years 2015 and 2018, which allows us to reflect on the contradictions of agribusiness and the resulting impacts of land appropriation by foreigners, such as deterritorialization of peasants and indigenous peoples, insecurity and loss of food sovereignty, population increase in slums and accentuation of rural and urban poverty, which shows that the impacts from the model are beyond the rural space.

KEYwORDs: Land foreignization; Land concentration; Territorial dispute; Geopolitics of the agrarian question.

\section{INTRODUÇão}

Este artigo é resultado da pesquisa de doutorado em Geografia em desenvolvimento intitulada "apropriação do território paraguaio por argentinos, brasileiros e uruguaios: controle de terras, estrangeirização e resistência camponesa" e do debate e reflexões possibilitadas durante a apresentação da investigação no VIII Simpósio sobre Reforma Agrária e Questões Rurais "Terra, Trabalho e Lutas no século XXI: projetos em disputa", realizado entre 06 e 08 de junho de 2018 na Universidade de 
Araraquara (UNIARA). O trabalho reflete ao tema proposto pelo simpósio, no qual questões históricas são recriadas no século XXI, aprofundando ainda mais disputas territoriais.

A partir de 2008 emerge em escala global o interesse em terras, impulsionado, em parte, por processos atuais de convergência de múltiplas crises: alimentar, ambiental, climática, energética e financeira; necessidade de ampliação do portfólio de investimentos do capital financeiro - para superar a crise de sobreacumulação (HARVEY, 2003) - e ascensão dos Middle Income Countries (MICs), ou seja, Países de Renda Média e blocos econômicos como BRICS (Brasil, Rússia, China e África do Sul) (MCKAY, 2017). Porém, apesar de muitas pesquisas abordarem o land rush como inédito, este é histórico, porque também é resultado da necessidade de acumulação do capital. Isto é, é um processo estrutural no movimento do capital no espaço e tempo.

Este interesse em terras resulta em diferentes impactos. O principal é que as terras alvo de tais transações são terras marginais ${ }^{3}$ do ponto de vista do capital (NALEPA, 2011), mas não no que se refere ao uso e ocupação. Há população habitando e se reproduzindo nas terras, mas com outro modelo de desenvolvimento, onde o objetivo é a sua reprodução e não a acumulação, como o capital. Isto gera uma disputa por territórios. A forma como o capital avança em terras é convencionalmente chamada pela academia internacional de land grabbing e acaparamiento de terras. Há uma diversidade de definições e entendimentos para este processo, variando de acordo com a área do conhecimento, recortes de análises e paradigmas.

Há pesquisadores que defendem a utilização da história para entender a atual dinâmica agrária (WILY, 2012; SASSEN, 2013; EDELMAN, 2016), outros abordam o land grabbing para além de investimentos em terras para agricultura, como em investimentos em infraestruturas (PEDLOWSKI, 2013), mineração (KINUTHIA,2013), turismo, green grabbing (FAIRHEAD, LEACH e SCOONES, 2012; HOLMES, 2014; LANDÍVAR e LLAMBÍ, 2016), embora haja análises agro-centricas (AKRAM-LODHI, 2011), ou seja, argumentam que o processo é envolve exclusivamente terras destinadas a agricultura; outros que defendem a relação entre land grabbing e acumulação primitiva (SASSEN, 2010; ADNAN, 2013; INCE, 2013) ou com a financeirização da agricultura (DANIEL, 2012; FAIRBAIRN,

O Banco Mundial (2011) compreende por terras marginais aquelas não cultivadas e não florestadas, com densidade populacionais inferior a 25 habitantes por quilômetro quadrado. Segundo este critério, haviam 445 milhões de hectares disponíveis para agricultura no globo (BANCO MUNDIAL, 2011)
2014; VISSER, 2015; FREDERICO, 2016). Há pesquisas orientadas para o dimensionamento dos impactos (OYA, 2013b; CUNHA, 2017), outras para as resistências (BORRAS JR e FRANCO, 2013; ALONSOFRADEJAS, 2015; MOREDA, 2015; GINGEMBRE, 2015; BUSCIOLI, 2016), há aquelas que explicitam a necessidade do capital estrangeiro no processo (ZOOMERS, 2010; SASSEN, 2016) e outras que criticam o termo estrangeirização como sinônimo de land grabbing (FAIRBAIRN, 2015). O único consenso entre as pesquisas é a intensificação desenfreada do land grabbing no século XXI (EDELMAN, OYA e BORRAS JR, 2013).

Embora se configure como um processo que atinge todo os países do globo (TNI, 2012; PLOEG, FRANCO e BORRAS JR, 2015; DESMARAIS, QUALMAN, MAGNAN e WIEBE, 2017), cada qual com suas particularidades, as nações do Sul global ainda são os principais alvos. Segundo a iniciativa LandMatrix ${ }^{4}$, apenas os continentes Americano e Africano possuem 26.946.703 hectares de terras transacionados, correspondendo a $65 \%$ de toda a superfície envolvida no land grabbing desde o início do século XXI. Nos países do Sul global, a questão da presença do capital estrangeiro assume um caráter relevante, visto que os agentes estrangeiros se configuram como os principais apropriadores de terras, compreendendo desde empresas até fundos de investimentos.

Este prévio debate nos mostra que a definição de land grabbing está em disputa por acadêmicos, instituições, movimentos sociais e governos. $\mathrm{Na}$ academia internacional não há um consenso sobre o papel do capital estrangeiro neste processo de disputa por território, embora as abordagens de estrangeirização sejam bastante criticadas (BORRAS JR, KAY, GÓMEZ e WILKINSON, 2012; OYA, 2013a; FAIRBAIRN, 2015), sob a justificativa de escamotear os agentes nacionais envolvidos no processo. No Brasil a situação é ainda mais complicada, pois não há uma tradução do termo land grabbing e se convencionou a utilizar o termo estrangeirização para se referir a tal processo.

A "grilagem" de terras tem sido uma constante na história agraria brasileira, caracterizada pela ocupação sucessiva de fronteiras por meio da apropriação de terras públicas ou da expulsão de populações munidas apenas de direitos consuetudinários. Para além da dimensão "em grande escala", frequente, porém não constitutiva desse processo, a noção de land grabbing cabe como uma luva para captar

$\overline{{ }^{4} \text { Dados coletados em } 1} 2$ jul. 2018. Disponível em: https://landmatrix.org/en/get-the-idea/agricultural-drivers/. 
a experiência brasileira de grilagem, mas pouco serve para identificar uma nova dinâmica. Como alternativa, os estudos brasileiros ressaltam outro aspecto desses investimentos - a sua condução por atores e capitais estrangeiros - e preferem a terminologia "estrangeirização" (WILKINSON, 2017, p. 13 - Grifo nosso).

Diante desta discussão defendemos que land grabbing e estrangeirização da terras não são sinônimos, uma vez que o primeiro diz respeito a um processo amplo de apropriação de terras e a estrangeirização é um elemento deste processo mais amplo, ou seja, é a apropriação de terras pelo capital estrangeiro. Nossa principal crítica ao land grabbing, é que este, por vezes, é utilizado de maneira restrita, pois é disseminada a ideia de terra enquanto superfície territorial e não concebem a terra enquanto território, que envolve outros recursos (água, biodiversidade, subsolo, fertilidade, entre outros) e relações sociais. Muitas vezes terras são transacionadas para que o capital possa ter acesso a estes recursos e não somente pela terra em si $i^{5}$. Neste sentido, propomos que uma tradução adequada para o land grabbing é o controle do território, pois o objetivo do capital é controle para promover a acumulação e a estrangeirização da terra representa um elemento desde processo, corresponde ao controle do território pelo capital estrangeiro.

No Sul Global, a questão que se sobressaí como elemento do controle de terras e estrangeirização é a concentração fundiária e, em algumas regiões, como é o caso da América Latina, é um pilar para entender o avanço do capital estrangeiro (BORRAS JR, KAY, GÓMEZ e WILKINSON, 2012). Neste contexto de aprofundamento da estrangeirização e concentração da terra que está inserido o Paraguai, país que possuí a maior concentração fundiária do mundo, com o índice de Gini de 0,93 (MAG, 2018). Concomitantemente, $19 \%$ do território paraguaio estava (em 2008) em posse de estrangeiros (GLAUSER, 2009) e que se configura como o terceiro maior exportador e sexto maior produtor de soja do globo (CAPECO, 2018).

Apesar desta conjuntura atual, a concentração e estrangeirização da terra no Paraguai se configuram como processos históricos, desde o final da Guerra da Tríplice Aliança (1864-1870) e que com o passar do tempo tornam-se mais complexos, interagindo ainda mais com processos econômicos e políticos globais (ARRIGHI, 2008). A situação atual do

${ }^{5}$ Um exemplo evidente é o caso da PEC 97, que propõe a cobrança de royalties do vento, impulsionada pelo
boom de empresas estrangeiras investindo na aquisição de terras para a implantação de projetos eólicos no boom de empresas
nordeste do Brasil.
Paraguai é reflexo do histórico processo de apropriação do seu território pelo capital estrangeiro. Galeano (1990, p. 07) argumenta que "las grandes alternativas y los más importantes problemas o desafíos estuvieron - y continúan estando - directamente relacionados con las consecuencias de los modos de apropiación y uso de la tierra". Assim, afirmamos que o Paraguai atual é fruto dos diversos territórios e territorialidades do controle e estrangeirização da terra nos diferentes períodos ao longo do seu processo de formação socioespacial.

No Paraguai é possível identificar três ciclos de estrangeirização da terra, todos estes marcados pela concentração fundiária e de renda. O primeiro de 1870 até 1950 , caracterizado pela venda de terras públicas e presença do capital argentino para a exploração do Quebracho ${ }^{6}$. Um segundo ciclo de 1950 até 1990, com reorientação das relações internacionais do Paraguai para o Brasil e marcado pelo início do cultivo de soja no país na década de 1970 e, por fim, o terceiro ciclo, iniciado na década de 1990 e que perdura até a atualidade, no qual há a transnacionalização definitiva do território paraguaio (VILLAGRA, 2014), intensificação da concentração e estrangeirização e da terra e acirramento dos conflitos pelo território era agronegócio e agricultura camponesa.

Assim, o objetivo deste artigo é debater acerca do processo histórico de apropriação do território paraguaio por estrangeiros desde 1870 até o período atual, evidenciando a sua relação com a concentração da estrutura fundiária no país. Entender este processo histórico é essencial para compreender as raízes da atual concentração da terra, estrangeirização do território e transformações agrárias ocorrentes no Paraguai. Para atingir este objetivo, para além de revisão bibliográfica, utilizamos dados de diferentes agências de pesquisas e entrevistas construídas durante trabalho de campo em diferentes departamentos paraguaios entre os anos de 2015 e 2018, que nos permite refletir acerca das contradições do agronegócio e dos impactos resultantes desta apropriação de terras por estrangeiros, tais como desterritorialização de camponeses e indígenas, insegurança e perda da soberania alimentar, aumento da população em favelas e acentuação da pobreza rural e urbana, o que evidencia que os impactos desde modelo estão para além do espaço rural. Sobre os dados de concentração e estrangeirização da terra, ressaltamos que há uma defasagem de dez anos, pois o Paraguai

${ }^{6}$ Quebracho é uma árvore natural da América do Sul utilizada para a extração do Tanino, substância usada no curtimento de couro. 
não realizou outro Censo Agrocupecuario Nacional, mas a tendência é que processos tenham se acentuado.

O artigo está organizado em três sessões, uma para cada ciclo de estrangeirização do território anteriormente citados, elencando as caraterísticas, papel do Estado, estratégias do capital e impactos territoriais, especialmente no que se refere a concentração fundiária em cada período. É necessário entender que a estrangeirização do território paraguaio é resultado de processos globais e regionais em interação com processos locais, ou seja, as interações espaciais multiescalares em diferentes contextos. Não é possível compreender as transformações agrárias no Paraguai sem considerar processos regionais, pois a questão agrária ultrapassa fronteiras políticas, indicando uma Geopolítica da Questão Agrária.

\section{Primeiro CiClo da eSTRANGeIRIZaÇão da TERRa: 1870-1950}

De 1811 até 1870 o Paraguai vive um período independente não apenas da Coroa Espanhola como também da Inglaterra, potência hegemônica da época (ARRIGHI, 2008; VILLAGRA, 2012). Esta fase da economia e política paraguaia pode ser dívida em dois momentos: o primeiro entre 1814 e 1840 em que Dr. Gaspar Rodríguez de Francia governou o país e o segundo entre 1842 e 1870 em que o Paraguai foi comandado por Carlos António López e posteriormente o seu filho, Francisco Solano López, que foi executado ao final da Guerra da Tríplice Aliança. A política de Francia se deu através de um modelo autônomo de desenvolvimento estatal, afirmando que o Paraguai poderia se desenvolver sem se relacionar com os países vizinhos, no caso Argentina e Brasil.

Com a política de Francia o Paraguai se tornou autossuficiente na produção agrícola e pecuária, erradicando a economia de monocultivos para a exploração, prática herdada do período colonial e fortaleceu o campesinato, que se estabeleceu como classe social mais numerosa do país (GALEANO, 2011; BOFILL, 2012). Segundo Villagra (2012) praticamente toda a população paraguaia estava inclusa neste modelo de desenvolvimento, não havia a fome e nem o desemprego "desde que el Paraguay no necesitaba de ellos (los países vecinos) y se bastaba a sí mismo" (VILLAGRA, 2012, p. 10).

El cambio de la estructura de la tenencia de la tierra, en la propiedad y en las relaciones de producción, permitieron la construcción de un modelo económico y político más sólido y soberano, con una clara proyección hacia una sociedad más incluyente e igualitaria, donde se priorizaba el mercado interno frente a la demanda internacional y la diversificación productiva frente a los monocultivos. Esta política se reflejó en las estadísticas comerciales: aún en el periodo colonial, en 1808, las exportaciones de yerba mate fueron de 327.150 arrobas, mientras, que para el año de 1839, las mismas solo fueron de 9.084 arrobas (VILLAGRA, 2014, p. 39).

Este modelo de desenvolvimento autônomo e economia pouco permeável, impedindo a apropriação do território pelo capital estrangeiro, culminaram na intervenção no Paraguai através da Guerra da Tríplice Aliança, em que Argentina, Brasil e Uruguai com o total apoio da Inglaterra lutaram contra o Paraguai ${ }^{7}$ entre 1864 e 1870. Existem diferentes interpretações sobre o que culminou de fato na Guerra, a mais disseminada é que a as nações da Tríplice Aliança e a Inglaterra, teriam receio do expansionismo paraguaio na região e por isso impulsionaram a Guerra (MOTA, 1995). Nas palavras de Hobsbawn (1988), o Paraguai tentou sair da esfera do mercado, porém foi massacrado e obrigado a reingressar.

Com o final da Guerra em 1870 o Paraguai estava devastado demográfica ${ }^{8}$, política e economicamente. O Estado, naquele momento, era proprietário de 30.429.375 hectares, onde o uso do solo era dividido em: 16.031 .250 hectares de bosques, 13.500.000 de campos, 1.575 de yerbales e apenas 489.375 hectares eram terras privadas. Para arcar com as dívidas da Guerra, o governo optou pela promulgação de leis de venda de terras públicas. Diferentes leis foram promulgadas entre 1871 e 1876, porém sem sucesso efetivo (PASTORE, 1972; KLEINPENNING, 1984). Já em 1883 e 1885 foram criadas duas leis que instauraram de fato a propriedade privada da terra e permitiram a criação de latifúndios e de uma classe de camponeses sem-terra: conhecidas como Leyes de Venta de Tierras Públicas (PASTORE, 1972; FOGEL, 2001).

A Lei de 1883 dividiu toda a região Oriental em três classes de área de acordo com o a localização e densidade de ocupação do solo. Enquanto a lei de 1885 classificou todo o Paraguai em cinco categorias utilizando os mesmos critérios (PASTORE, 1972). Segundo Kleinpenning (2014), entre

Daniel Campos (2012, p. 01) coloca que "en realidad escondía y representaba una alianza quíntuple del capital internacional inglés con la oligarquía argentina, brasilera, uruguaya y paraguaya”.

${ }^{8}$ No início da Guerra a população paraguaia estava estimada em 800.000 habitantes e em 1872 a população total do país era de 231.196 habitantes (PASTORE, 1972). 
1885 e 1914 foram vendidos 24.700 .000 hectares do território paraguaio, especialmente a estrangeiros - que eram aqueles que tinham condições de comprar as terras - totalizando US\$ $10.600 .000,00$, isto é, abaixo do preço de mercado. O Estado paraguaio não tinha controle algum sobre o processo e, inclusive, vendia terras com habitantes no seu interior. No início da promulgação das leis, a classe camponesa paraguaia tinha preferência na aquisição das terras, mas para esta era impossível porque o prazo para a compra era curto e a extensão mínima a ser adquirida era de 1.825 hectares (KLEINPENNING, 2014).

El resultado fue que se fomentó aún más el latifundismo y no se dio a los pequeños y medianos agricultores la oportunidad de mejorar su posición. Muchos campesinos, por consiguiente, se volvieron dependientes delos nuevos dueños en calidad de pequeños arrendatarios y trabajadores zafrales (...) El resultado fue que la gran mayoría de la población dedicada a la agricultura (no menos de $83 \%$ de la población económicamente activa en 1886) continuaba sin título de propiedad oficial y debía subsistir como arrendatarios u ocupantes en las pequeñas tierras fiscales que quedaban; como intrusos en tierras privadas; o como trabajadores estacionales (KLEINPENNING, 2014, p. 395-396).

No que tange a concentração fundiária do período, segundo os dados disponibilizados pela Biblioteca Nacional de Agricultura, do MAG, em 1921 haviam 32.746.713 hectares agricultáveis - embora a prática agrícola não era expressiva no país neste momento - divididos em 36.233 propriedades, como nos mostra a Tabela 01. Em 1921 já é possível verificar a concentração da terra em torno dos latifúndios, onde 604 propriedades com mais de 10.000 hectares $(1,64 \%)$ detinham 24.922 .310 , ou seja, $76,11 \%$ do território agricultável do país; enquanto as propriedades de 01-10 hectares correspondiam a $17.315(47,79 \%)$, somando 78.765 hectares, o que equivale a $0,24 \%$ da área total agricultável de 1921.

As leis de venda de terras públicas não cumpriu com o seu objetivo de gerar divisas para saldar os empréstimos internacionais e ao início dos anos 1900 o Paraguai novamente estava em débito e, desta vez, sem terras (KLEINPENNING, 2014). Dentre os compradores de terra estavam, na sua maioria, empresas e pessoas físicas argentinas interessadas na exploração do quebracho para a extração do tanino.
Tabela 01 - Distribuição de propriedades de acordo com o tamanho (HA) $-1921$.

\begin{tabular}{c|c|c|c|c}
\hline $\begin{array}{c}\text { Tamanho das } \\
\text { propriedades } \\
\text { (HA) }\end{array}$ & $\begin{array}{c}\text { Quantidade } \\
\text { de proprie- } \\
\text { dades }\end{array}$ & $\begin{array}{c}\text { \% de pro- } \\
\text { priedades }\end{array}$ & $\begin{array}{c}\text { Superfície } \\
\text { (HA) }\end{array}$ & $\begin{array}{c}\text { \% em re- } \\
\text { lação à } \\
\text { superfície } \\
\text { total }\end{array}$ \\
\hline $\mathbf{0 1 - 1 0}$ & 17.315 & 47,79 & 78.765 & 0,24 \\
\hline $\mathbf{1 1 - 4 9}$ & 10.778 & 29,75 & 222.953 & 0,68 \\
\hline $\mathbf{5 0 - 4 9 9}$ & 4.825 & 13,32 & 868.019 & 2,65 \\
\hline $\mathbf{5 0 0 - 9 9 9}$ & 854 & 2,36 & 625.707 & 1,91 \\
\hline $\mathbf{1 . 0 0 0}-\mathbf{4 . 9 9 9}$ & 1.517 & 4,19 & 3.533 .619 & 10,79 \\
\hline $\mathbf{5 . 0 0 0}-\mathbf{9 . 9 9 9}$ & 340 & 0,94 & 2.495 .340 & 7,62 \\
\hline $\begin{array}{c}\text { Maior de } \\
\mathbf{1 0 . 0 0 0}\end{array}$ & $\mathbf{6 0 4}$ & $\mathbf{1 , 6 4}$ & $\mathbf{2 4 . 9 2 2 . 3 1 0}$ & $\mathbf{7 6 , 1 1}$ \\
\hline \multicolumn{4}{|c|}{ Fonte: MAG $(2018) ;$ Org.: PEREIRA $(2018)}$. \\
\hline
\end{tabular}

Este não foi um processo espontâneo, mas sim uma expansão das empresas britânicas que haviam se territorializado no nordeste da Argentina (e se constituído como empresas de capital argentino) anos antes para a exploração do quebracho "de esta forma, las empresas que extraían el quebracho en el norte argentino se posicionaron em el Chaco paraguayo, el cual se convirtió en un espacio que funcionaba según el modelo económico argentino" (VÁZQUEZ, 2005, p. 72). A Argentina assumiu um papel hegemônico na bacia do rio do Prata até meados da década de 1950 (YEGROS; BREZZO, 2013).

Outra questão importante é que além da geração de divisas, as leis de vendas de terras públicas, foi também uma estratégia geopolítica para povoar e definir fronteiras internacionais com a Bolívia, que só foram estabelecidas com a Guerra do Chaco $^{9}$ (1932-1935) (VÁZQUEZ, 2013; KLEINPENNING, 2014) e, de fato, a presença de empresas estrangeiras na região influenciou positivamente o Paraguai durante a Guerra (CABALLERO, 2014). O final da Guerra do Chaco coincidiu com o período de decadência da exploração do quebracho para a extração do tanino, devido ao baixo preço do tanino no mercado internacional, ao surgimento de novos produtos químicos para

${ }^{9} \mathrm{~A}$ Guerra do Chaco não foi apenas uma disputa pelo território do Chaco boreal entre a Bolívia e o Paraguai, mas também atendeu os interesses de corporações transnacionais como a estadunidense Standart Oil e a angloholandesa Royal Dutch Shell, que estavam interessadas na exploração de petróleo na região. 
o curtimento do couro e pela escassez do quebracho, que foi altamente explorado nos anos anteriores. Assim, durante a década de 1950 iniciou-se a retirada das empresas que exploravam o quebracho para a extração do tanino do Chaco. Algumas empresas se deslocaram ao continente africano e outras, simplesmente, pararam a exploração. Foi neste cenário que a agricultura e pecuária se consolidaram e expandiram na região. Neste cenário, emerge um novo ciclo de estrangeirização do território paraguaio.

\section{SEgUNDO CICLO DA ESTRANGEIRIZAÇÃo DA TERRA: 1950-1990}

A partir da década de 1950 inicia-se no Paraguai alterações econômicas, políticas e sociais profundas, deixando o país cada vez mais a disposição do capital estrangeiro. Em 1954 Alfredo Stroessner (Partido Colorado), assume a presidência do Paraguai através de um golpe de Estado e iniciando o período ditatorial no país que perdurou até 1989. Stroessner possuía uma política de relações internacionais pendular, isto é, ora negociava com a Argentina e ora com o Brasil, o que coincidiu com a ascensão do Brasil na região (YEGROS; BREZZO, 2013). Além de projetos de integração e infraestrutura entre os dois países como a construção da Ponte da Amizade (1965), rodovia conectando o Paraguai e o litoral do Paraná (1969) e da Usina Hidrelétrica Binacional de Itaipu (1973), outras políticas de incentivo aproximação entre Brasil e Paraguai a modificação do estatuto agrário em $1963^{10}$, permitindo a apropriação de terras paraguaias por estrangeiros na faixa de segurança fronteiriça $-150 \mathrm{~km}$ da fronteira - e em terras destinadas a reforma agrária (ALBUQUERQUE, 2010; MORAES; VIEIRA, 2015).

Contudo, a questão agrária ultrapassa fronteiras e não podemos compreender a intensificação da presença brasileira no Paraguai sem considerar a realidade brasileira daquele período (RIQUELME; KRETSCHEMER, 2016). Durante a década de 1950 o Brasil passa por um processo de modernização conservadora da agricultura que assolava sobretudo os estados da região Sul do país. Justamente neste cenário de modernização da agricultura no Brasil que se inicia o processo de migração de camponeses e grandes produtores para o Paraguai.

O Estado paraguaio, por sua vez, estava muito interessado na migração de brasileiros e assim exerceu um papel importante através o incentivo a colonização da Região Fronteiriça Oriental, com o objetivo de povoa-la. As

${ }^{10}$ Com o novo estatuto agrário extinguiu-se o Instituto de Reforma Agrária (IRA) e criou-se o Instituto de Bienestar Rural (IBR). Palau (2003) afirma que como Stroessner havia instaurado a Marcha hacia el Este em 1960, a reforma agrária no país já estava efetuada, restando agora o bem-estar rural.

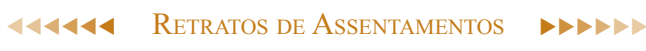

v.21, n.2, 2018 razões para a política de povoamento foram: motivos de ordem geopolítica, que estavam enquadrados na Doutrina de Seguridad Nacional, na qual o Estado deveria ocupar espaços vazios, onde espaço vazio é sinônimo de território fora do controle estatal; concentração de minifúndios e conflitos na região central do Paraguai e função modernizadora que cumpre o Estado (PALAU; HEIKEL, 1987, p. 33). Stroessner doou extensas superfícies de terras a brasileiros e paraguaios (não benificiários de reforma agrária) simpatizantes do seu governo, tais terras hoje são chamadas de tierras malhabidas e correspondem a 5.675.393 hectares, ou seja, 13,95\% do território paraguaio (BARRETO, 2006; HETHERINGTON, 2012; CAMPANHA TIERRAS MALHABIDAS, 2018). Além da doação, ocorreram créditos a longo prazo pelo Banco Nacional de Fomento (BNF) (ALBUQUERQUE, 2010).

Há divergências em torno do apoio do Estado paraguaio. Reportagens publicadas na época em jornais e revistas brasileiros, como a da Revista Veja de 24 set. 1975 evidenciam o importante papel do Estado na facilitação do acesso à terra e a créditos. Enquanto alguns pesquisadores paraguaios, durante trabalhos de campo, afirmam acerca da não existência de benefícios os brasileiros, apontando que tudo o que o capital brasileiro construiu no Paraguai foi por mérito. Isso nos mostra um debate paradigmático entre os próprios pesquisadores paraguaios, enquanto uns defendem o papel do Estado paraguaio (VILLAGRA, 2009, 2012 e 2014) outros defendem o contrário (VÁZQUEZ, 2013).

Ocorre que havia um fluxo convergente, porque durante a década de 1950 o governo do Paraguai institucionalizou um programa de colonização intitulado Marcha hacia el Este, com o objetivo de colonização da fronteira (questão Geopolítica), desconcentração fundiária e diminuição dos conflitos entre camponeses e latifundiários na região central do país - departamentos de Paraguarí, Cordillera, Central, Guairá e porções de Caazapá e Misiones - a chamada región campesina arraigada (KLEINPENNING; ZOOMERS, 1988; VÁZQUEZ, 2006). Deste modo, a Marcha hacia el Este no Paraguai coincidiu com a Marcha para o Oeste no Brasil. Isto gerou um problema fundiário no Paraguai que é sentido até a atualidade, porque os camponeses paraguaios foram duplamente desterritorializados: em um primeiro momento quando o Estado os desterritorializaram da região central para o Leste paraguaio e posteriormente quando brasileiros foram desterritorializados da região Sul do Brasil e reterritorializados no Paraguai, desterritorializando mais uma vez os camponeses paraguaios. A problemática da terra se 
acentuava cada vez mais porque com a venda de suas terras no Brasil, os camponeses brasileiros chegavam ao Paraguai com recursos para comprar uma extensão de terra maior do que eles possuíam antes e pelo fato do solo ser semelhante do Brasil, enquanto os paraguaios tiveram dificuldades no manejo do mesmo.

Os migrantes brasileiros eram heterogêneos ${ }^{11}$ (RIQUELME, 2005), havendo uma diferenciação entre estes: 1) euro-brasileiros, na sua maioria de origem alemã, dos estados do Sul do Brasil, estes eram medianos proprietários do tipo Farmer ${ }^{12}$, que foram desterritorializados do Brasil pela modernização da agricultura e que migraram para o Paraguai. Eram produtores com maiores recursos, com facilidade do acesso a crédito e que se tornaram produtores de soja; 2) camponeses, meeiros e arrendatários, constituído por migrantes oriundos do nordeste do Brasil, que já haviam migrado para o Sul do país em busca de melhor qualidade de vida de trabalho e que agora [década de 1970] estavam migrando para o Paraguai. Estes camponeses eram pobres e logo retornaram ao Brasil na condição de sem-terra (PALAU; HEIKEL, 1987).

Muitos dos produtores da primeira classe constituíram empresas no Paraguai, como é o exemplo de Tranquilo Favero, que em 1972 criou um grupo empresarial chamado Grupo Favero, que atualmente possui nove empresas territorializadas em dez departamentos do país, todas destinadas a produção, processamento e comercialização de soja e é considerado o Rei da Soja, estando envolvido em diferentes conflitos. Outras empresas brasileiras também iniciaram suas atuações no país vizinho, como exemplo da Agrociencia S.A. Outras iniciaram atividades, mas logo fecharam, como o caso da FINAP SRL e Madepar (PEREIRA, 2017).

A questão crucial da migração de produtores brasileiros para o Paraguai é a introdução do cultivo da soja no país na década de 1970. Segundo dados do Ministerio de Agricultura y Ganadería, em 1973 o Paraguai possuía 15.500 hectares de soja cultivados e já na década de 1980 haviam conflitos resultantes da expansão da soja em toda fronteira leste do Paraguai (VILLAGRA, 2009). Deste modo, é possível afirmar que o cultivo de soja no país e o seu desenvolvimento está diretamente relacionado com a

\footnotetext{
${ }^{1}$ Muitos dos migrante brasileiros no Paraguai ficaram conhecidos como brasiguaios. Durante o trabalho de campo frequentemente os paraguaios se referiam aos brasiguaios como aqueles produtores brasileiros que se desenvolvermuno pás. Poŕm, no Brail, as pesquisas getale cesenveram dos brasiguaios é intensa até a atualidade, embora não seja objetivo deste trabalho.

${ }^{12}$ Segundo Riquelme e Kretschmer (2016) são aqueles com propriedades entre 50 e 1.000 hectares.
}

estrangeirização do território paraguaio. Junto com a migração brasileira para o Paraguai e com a territorialização de empresas estrangeiras e transnacionais no país, ocorreu a acentuação da concentração fundiária, conforme evidencia a Tabela 02.

Tabela 02 - Distribuição de propriedades de acordo com o tamanho (HA) $-1981$.

\begin{tabular}{c|c|c|c|c}
\hline $\begin{array}{c}\text { Tamanho } \\
\text { das proprie- } \\
\text { dades (HA) }\end{array}$ & $\begin{array}{c}\text { Quantidade de } \\
\text { propriedades }\end{array}$ & $\begin{array}{c}\text { \% de pro- } \\
\text { priedades }\end{array}$ & Superfície (HA) & $\begin{array}{c}\text { \% em } \\
\text { relação à } \\
\text { superfície } \\
\text { total }\end{array}$ \\
\hline Menor de 05 & 82.376 & 34,09 & 169.137 & 0,77 \\
\hline $\mathbf{0 5}-\mathbf{0 9}$ & 49.511 & 20,49 & 322.050 & 1,47 \\
\hline $\mathbf{1 0}-\mathbf{1 9}$ & 56.476 & 23,37 & 694.190 & 3,16 \\
\hline $\mathbf{2 0}-\mathbf{4 9}$ & 36.007 & 14,90 & 942.358 & 4,30 \\
\hline $\mathbf{5 0}-\mathbf{1 9 9}$ & 11.020 & 4,56 & 1.003 .558 & 4,57 \\
\hline $\mathbf{2 0 0}-\mathbf{4 9 9}$ & 2.920 & 1,21 & 858.794 & 3,91 \\
\hline $\mathbf{5 0 0}-\mathbf{9 9 9}$ & 1.053 & 0,44 & 707.007 & 3,22 \\
\hline $\mathbf{1 . 0 0 0}-\mathbf{4 . 9 9 9}$ & 1.599 & 0,66 & 3.393 .980 & 15,57 \\
\hline $\mathbf{5 . 0 0 0}-\mathbf{9 . 9 9 9}$ & 366 & 0,15 & 2.522 .440 & 11,50 \\
\hline Maior de & 324 & 0,13 & 11.327 .016 & 51,63 \\
$\mathbf{1 0 . 0 0 0}$ & $\mathbf{2 4 1 . 6 5 2}$ & $\mathbf{1 0 0}$ & $\mathbf{2 1 . 9 4 0 . 5 3 0}$ & $\mathbf{1 0 0}$ \\
\hline Total & \multicolumn{2}{|c|}{ Fonte: MAG $(1981) ;$ Org.: PEREIRA (2018). }
\end{tabular}

A concentração fundiária foi proporcionada pelo baixo preço da terra na região oriental do Paraguai. De acordo com entrevistas realizadas durante trabalho de campo com a população paraguaia, em 1970 o preço de um hectare de terra era de US\$40,00, o equivalente a Gs. 540.00,00, ou seja, um valor absurdamente barato para os brasileiros e demais capitais interessados na apropriação de terras no Paraguai e muito dinheiro para camponeses paraguaios que não possuíam recurso algum. Assim, os dados apresentados na Tabela evidenciam que a concentração fundiária está diretamente relacionada com a territorialização do agronegócio brasileiro no Paraguai.

Durante este segundo ciclo, o campesinato paraguaio já estava começando a sua organização em movimentos socioterritoriais, como o caso das Ligas Agrarias Cristianas (LACs) na década de 1970 (MORÍNGO, 2003; 
TALESCA, 2004), contudo estes eram violentamente reprimidos pelo Estado, pois durante a ditadura as organizações sociais eram consideradas um perigo a política de segurança nacional (MORA, 2006). Este cenário altera com a abertura democrática em 1989, iniciando o terceiro ciclo de estrangeirização do território paraguaio, no qual não apenas o campesinato possuía mais liberdade na luta pela terra, mas também o capital através do avanço do neoliberalismo no Paraguai.

TERCEIRO CIClO Da ESTRANGEIRIZAÇÃo DA TERRA: 1990 - ATUAL

A década de 1990 foi marcada por uma série de mudanças que aprofundaram ainda mais a estrangeirização e concentração da terra no Paraguai. Neste período ocorreu uma crise econômica que assolou toda a América Latina e a resposta da maior parte dos Estados, inclusive do Paraguai, no momento governado pelo presidente Juan Carlos Wasmosy (1993-1998), foi a implementação de políticas neoliberais (VILLAGRA, 2012), que expandiu ainda mais o cultivo de soja. No final da década de 1990 a questão se agrava, pois se inicia ilegalmente no Paraguai o cultivo de soja transgênica, contrabandeada da Argentina (PALAU, 2008; VILLAGRA, 2009). O resultado é que o Paraguai apresenta vinte anos de crescimento ininterruptos de soja, se tornando o sexto maior produtor e terceiro maior exportador do grão, onde a projeção para a safra de 2017/2018 é de 3.400 .000 hectares cultivados, totalizando 9.500 .000 toneladas produzidas;

Esta dinâmica aumenta a concentração da terra, pois empresas e médios e grandes produtores de soja que se estabeleceram na região fronteiriça Oriental durante a década de 1970 e 1980 passam a expandir sua atuação no país para outros departamentos, aumentando o seu território, a produção de soja e a concentração de terras e de renda. A Tabela 03 evidencia a estrutura fundiária nos anos de 1991 e $2008^{13}$

Em 1991 o Paraguai possuía 299.259 propriedades, totalizando 23.817.736 hectares disponíveis à agricultura, no qual as propriedades menores a cinco hectares representavam $38 \%$ de todas as propriedades do Paraguai, ao mesmo tempo que a sua superfície representava $1 \%$ de toda área agricultável. Enquanto as parcelas maiores de 10.000 hectares respondiam a $0,11 \%$ de todas as parcelas e concentravam $41 \%$ de toda terra disponível para a agricultura. No que tange a presença de proprietários brasileiros, estes controlavam $14 \%$ das propriedades acima de 1.000 hectares.

${ }^{13}$ Por falta de dados atualizados, utilizamos informações disponibilizados no último Censo Agropecuario Nacional (CAN), de 2008.
Tabela 03 - Distribuição de propriedades de acordo com o tamanho (HA) -1991-2008.

\begin{tabular}{c|c|c|c|l}
\hline \multirow{2}{*}{$\begin{array}{c}\text { Tamanho das } \\
\text { propriedades } \\
\text { (HA) }\end{array}$} & $\begin{array}{c}|c| \\
\text { Quantidade de } \\
\text { propriedades }\end{array}$ & $\begin{array}{c}\text { Superfície } \\
\text { (HA) }\end{array}$ & $\begin{array}{c}\text { Quantidade } \\
\text { de proprieda- } \\
\text { des }\end{array}$ & $\begin{array}{c}\text { Superfície } \\
\text { (HA) }\end{array}$ \\
\hline Menor de 05 & 114.788 & 231.304 & 117.229 & 238.012 \\
\hline $\mathbf{0 5}-\mathbf{0 9}$ & 66.605 & 430.658 & 66.218 & 416.702 \\
\hline $\mathbf{1 0}-\mathbf{1 9}$ & 66.223 & 806.802 & 57.735 & 685.381 \\
\hline $\mathbf{2 0}-\mathbf{4 9}$ & 31.519 & 857.909 & 22.865 & 619.986 \\
\hline $\mathbf{5 0}-\mathbf{1 9 9}$ & 11.856 & 1.071 .817 & 12.113 & 1.158 .812 \\
\hline $\mathbf{2 0 0}-\mathbf{4 9 9}$ & 3.503 & 1.050 .034 & 5.251 & 1.600 .537 \\
\hline $\mathbf{5 0 0 - 9 9 9}$ & 1.525 & 1.010 .952 & 2.737 & 1.810 .119 \\
\hline $\mathbf{1 . 0 0 0}-\mathbf{4 . 9 9 9}$ & $2 . .356$ & 4.982 .438 & 3.443 & 7.200 .531 \\
\hline $\mathbf{5 . 0 0 0}-\mathbf{9 . 9 9 9}$ & 533 & 3.644 .873 & 684 & 4.702 .034 \\
\hline Maior de 10.000 & 351 & 9.730 .949 & 600 & 12.654 .779 \\
\hline Total & $\mathbf{2 9 9 . 2 5 9}$ & $\mathbf{2 3 . 8 1 7 . 7 3 6}$ & $\mathbf{2 8 8 . 8 7 5}$ & $\mathbf{3 1 . 0 8 6 . 8 9 3}$ \\
\hline
\end{tabular}

Fonte: MAG (1991; 2008); Org.: PEREIRA (2018)

Já no ano de 2008 haviam 288.875 propriedades registradas no Paraguai, somando 31.086.893 hectares, o que significa uma diminuição no número de propriedades em 10.384 e aumento de 7.269.177 hectares de áreas agrícolas em relação a 1991. A concentração fundiária se acentuou, as propriedades menores de cinco hectares correspondiam a $40,58 \%$ do total e a sua área representava $0,77 \%$, ao mesmo tempo que os estabelecimentos maiores que 10.000 hectares representavam $0,21 \%$ em relação ao total de propriedades e sua área $40,71 \%$ em relação ao total de terras agricultáveis. Sobre a presença de estrangeiros, em 2008 somente os brasileiros controlavam $25 \%$ de todas as propriedades acima de 1.000 hectares do Paraguai. As Pranchas 01 e 02 representam a concentração da propriedade e da superfície respectivamente.

Podemos concluir que os departamentos com predomínio de propriedades menores a 20 hectares são: Central (96,7\%), Cordillera (94,2\%), Guairá (92,4\%), Paraguarí (90\%), Caazapá (89,9\%), San Pedro (89,8\%), Caaguazú (89,5\%), Concepción (83\%), Misiones (82,6\%) e Itapúa (81,5\%).

v.21, n.2, $2018 \quad 444444$ Retratos De Assentamentos $\gg \gg \gg \longmapsto$ 
Prancha 01 - Concentração da propriedade da terra por departamento 2008.

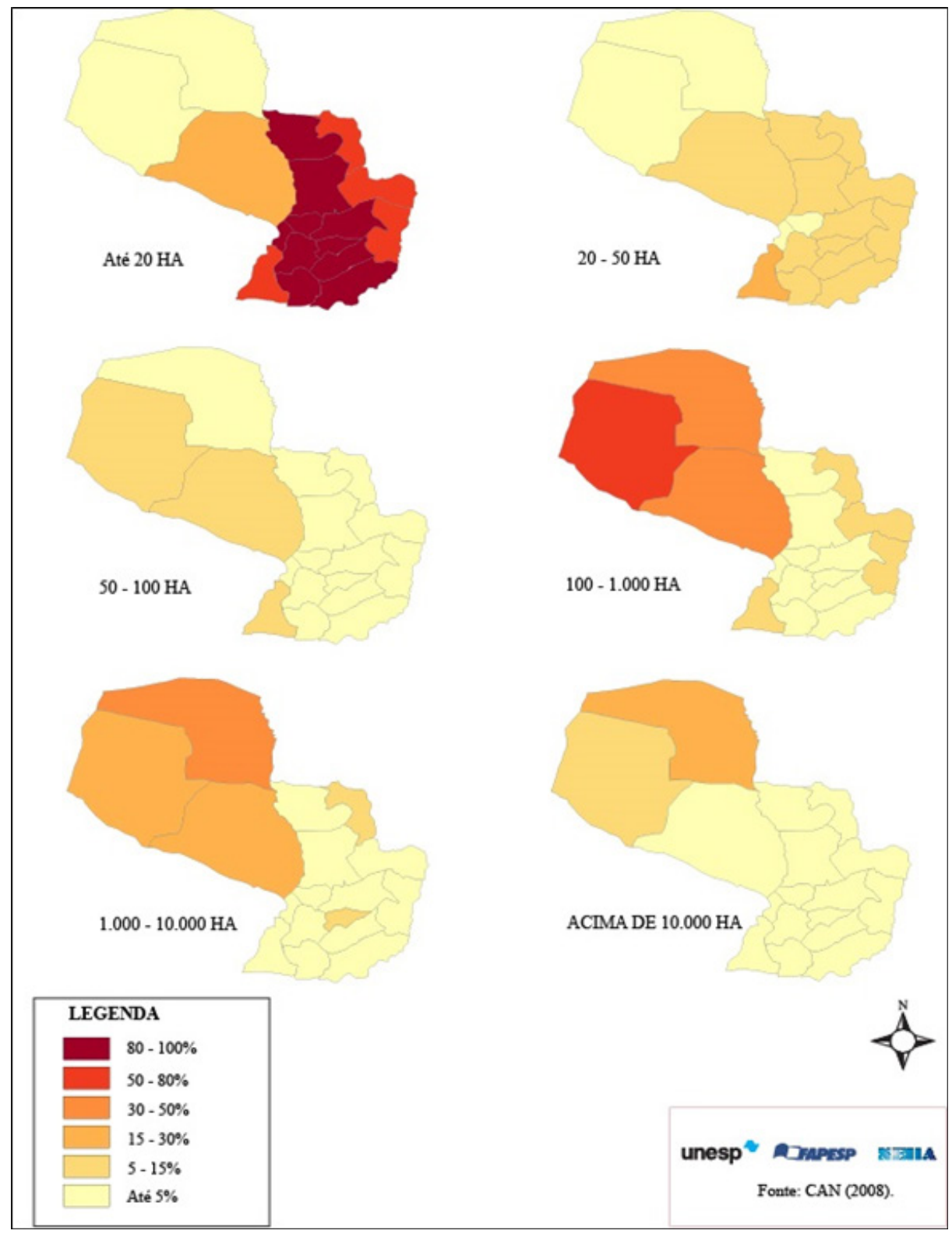

Fonte: MAG (2008); Org.: PEREIRA (2018).
Prancha 02 - Concentração da superfície disponível para agricultura por departamento -2008 .

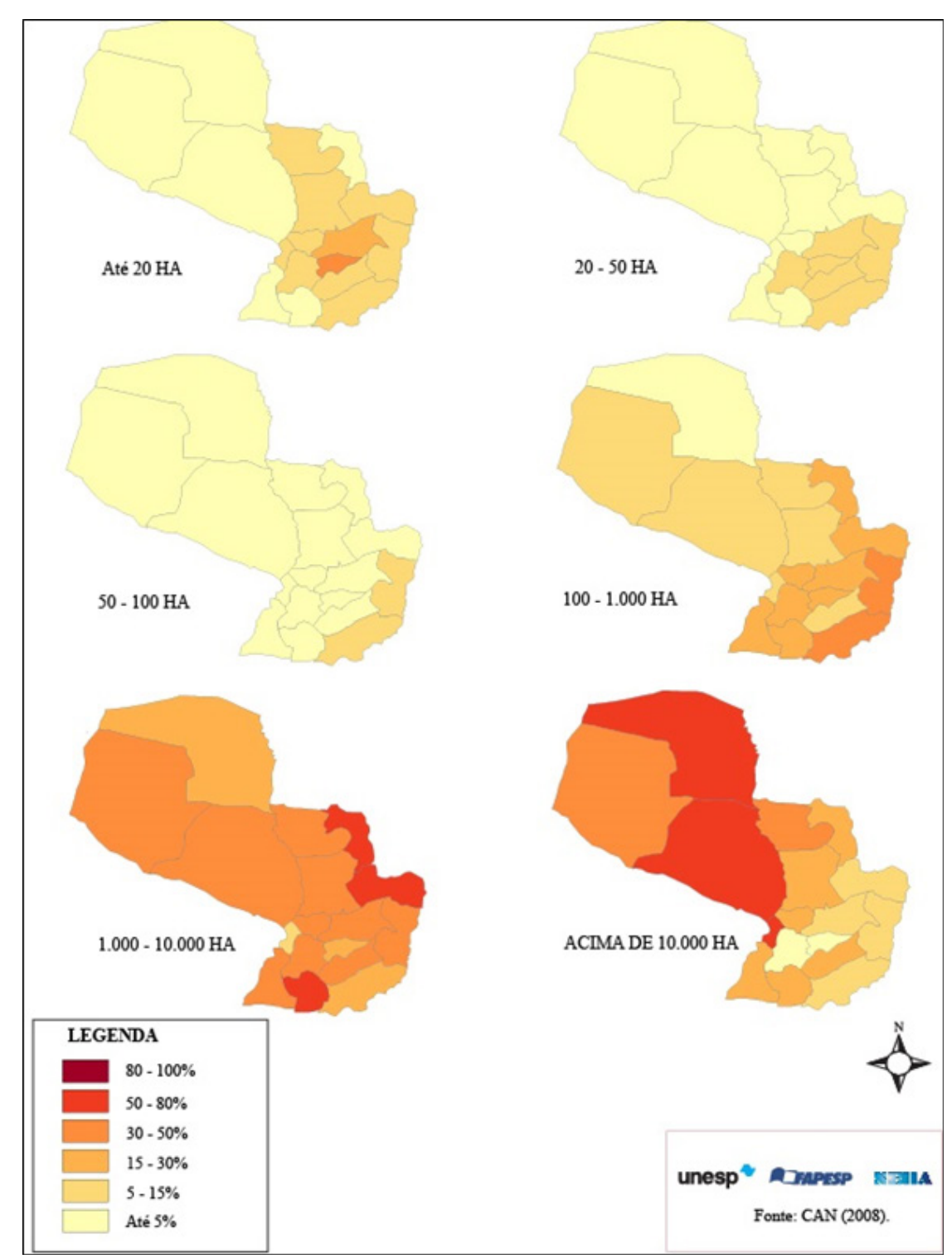


Mapa 01 - Porcentagem de terra em posse de brasileiros de acordo com o departamento - 2008 .

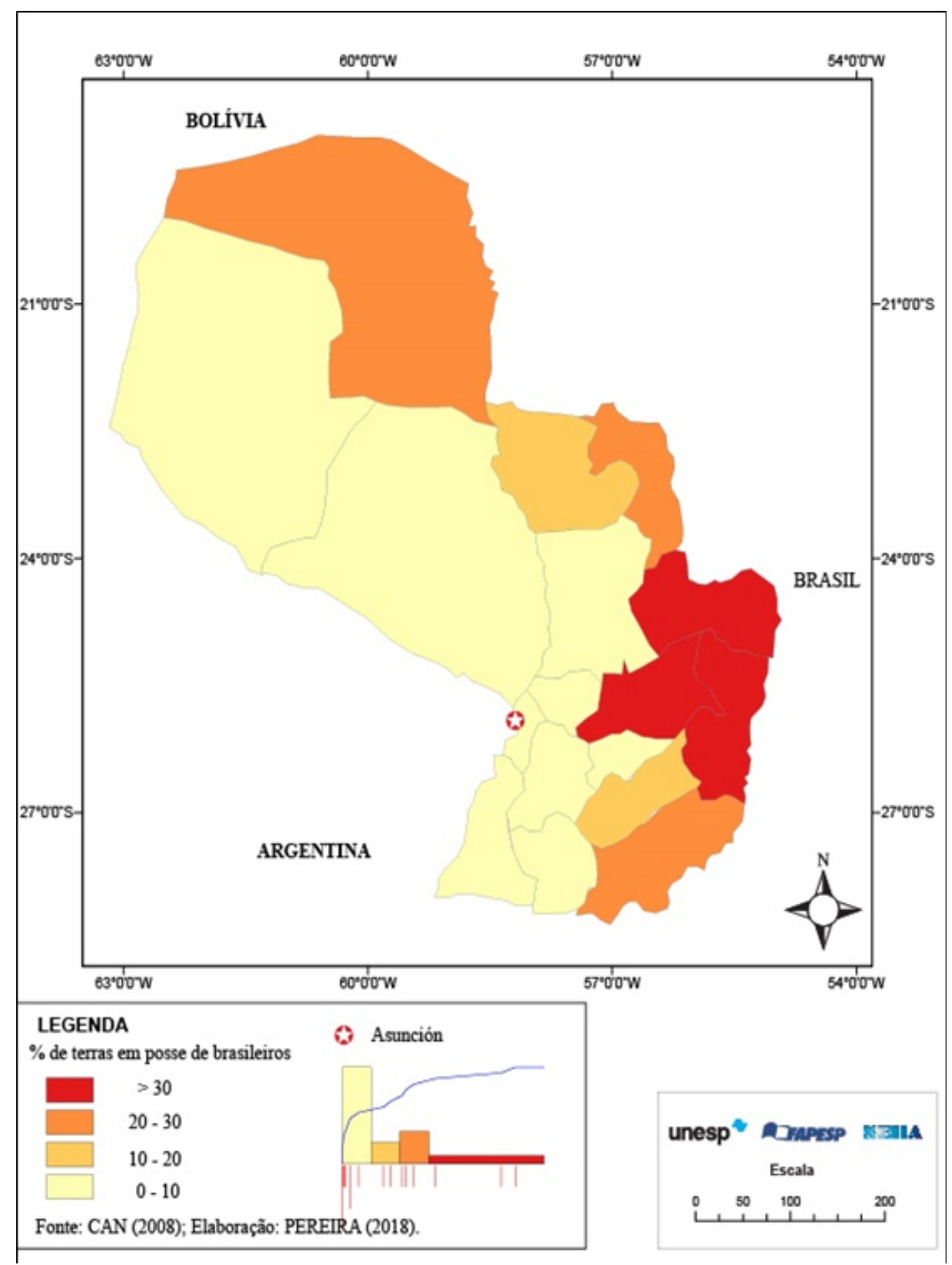

Fonte: MAG (2008); Org.: PEREIRA (2018).
Mapa 02 - Porcentagem de terra em posse de outros capitais de origem acordo com o departamento -2008 .

\section{PARAGUAI - PORCENTAGEM DE TERRA EM POSSE DE OUTROS} CAPITAIS POR DEPARTAMENTO - 2008

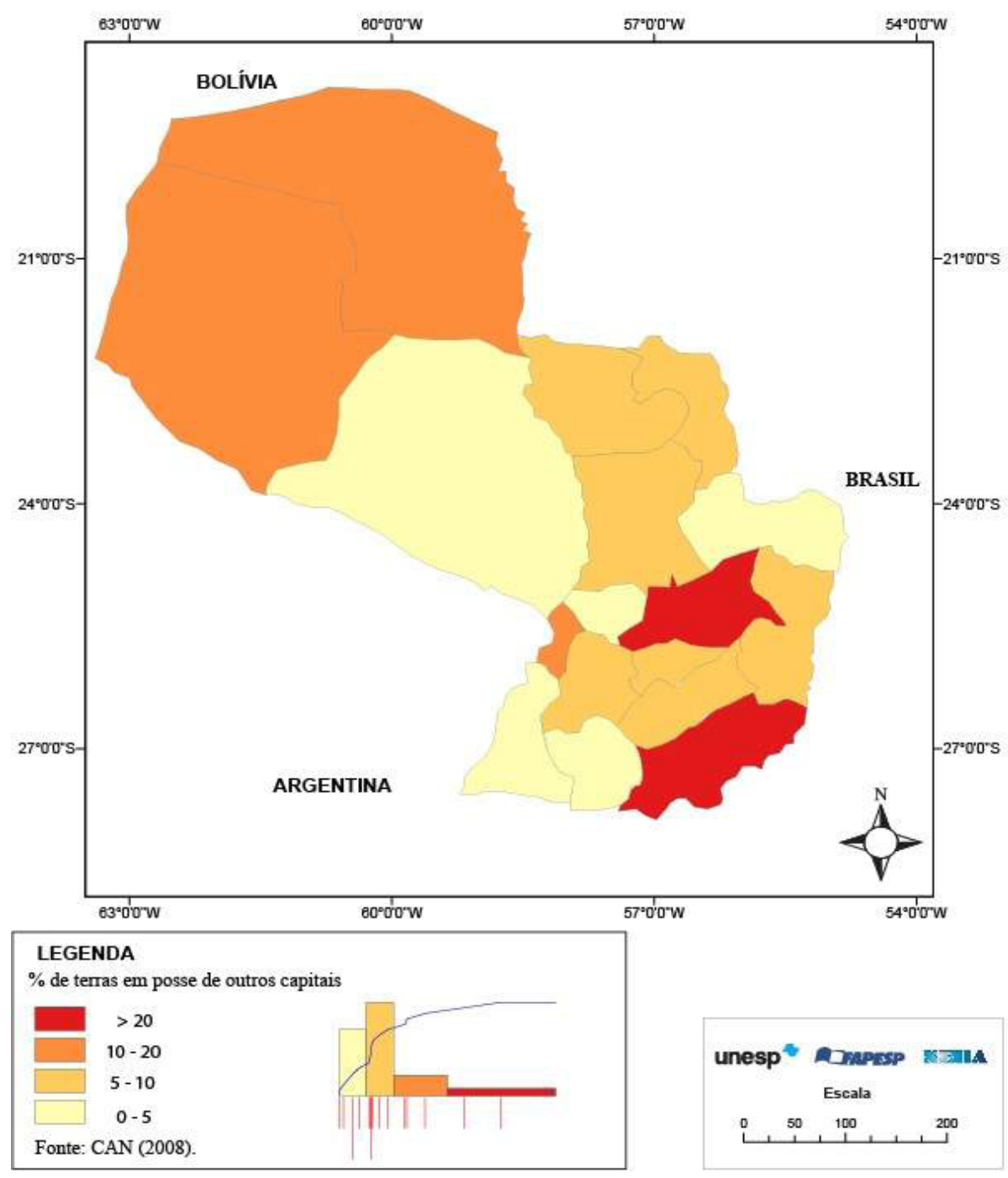

Fonte: MAG (2008); Org.: PEREIRA (2018).. 
Os departamentos nos quais há uma concentração do minifúndio - região central - correspondem aos maiores produtores de alimentos do país, ou seja, é resultado da agricultura familiar camponesa, ressaltando que o país cultiva aproximadamente apenas 300.000 hectares de alimentos enquanto produz 3.600.000 hectares de soja. Já departamentos da região fronteiriça Oriental e do Chaco Paraguaio - Alto Paraguay, Boquerón e Presidente Hayes - concentram as maiores propriedades ${ }^{14}$.

Com o Mapa 01 podemos observar que os departamentos de Canindeyú e Alto Paraná, fronteiriços com o Brasil, apresentam 60,1\% e 55,2\% do seu território, respectivamente, em posse de brasileiros, seguido do departamento de Caaguazú, na região central, com $32,1 \%$ do superfície territorial em mãos de brasileiros. Outros departamentos fronteiriços como Brasil, como Amambay e Itapúa, apresentam respectivamente $24,8 \%$ e 20,7\% de terras em posse de brasileiros. O departamento de Alto Paraguay também se destaca, apresentando $22 \%$ do seu território em posse de brasileiro em 2008.

Esta porcentagem é interessante, uma vez que representa o avanço da fronteira agrícola em direção ao Chaco. Os departamentos de Concepción e Caazapá também apresentaram em 2008 uma significativa superfície de terras em posse de brasileiros, $16,7 \%$ e $14,3 \%$, respectivamente, seguidos de Guairá, com 5,6\% e Misiones e San Pedro, ambos com 2,6\%. Segundo o Censo Agropecuario Nacional, em 2008 não havia nenhum hectare de terra em posse de brasileiros no departamento de Ñeembucú, situação na qual já sabemos que não faz mais parte da realidade, um exemplo é o caso da empresa brasileira Villa Oliva Rice S.A. que se territorializou no departamento em 2015 para a produção de arroz, causando uma diversidade de impactos ambientais.

No caso das terras em posse de outros capitais de origem, destacamos os departamentos de Caaguazú, com 29,8\% - que somando com as terras em posse de brasileiros possuía em 2008 61,9\% de seu território em posse de estrangeiro, ou seja, mais da metade do departamento estava sob o controle do capital estrangeiro e a estimativa é que esta porcentagem tenha aumentado. Seguidos dos departamentos de Boquerón e Alto Paraguay, com 15,9\% 3 12,1\% respectivamente, nestes departamentos localizados na fronteira agrícola os capitais argentinos e uruguaios apresentam grandes propriedades de terra.

\footnotetext{
${ }^{4}$ No caso do Chaco Paraguaio, todo seu processo de apropriação foi caracterizado pela concentração da terra É necessário enfatizar que esta região corresponde a $69 \%$ de todo o território paraguaio e é habitada apenas por $3 \%$ de toda população paraguaia.
}

Assim como nos anos de 1921 e 1981, a tendência se repete: a concentração fundiária avança de acordo com a expansão da estrangeirização da terra no Paraguai. Segundo Glauser (2009), o capital estrangeiro controlava direta e indiretamente $19 \%$ do território paraguaio em 2008 . Estas dados apresentam dez anos de defasagem, onde muito alterou-se. Além do ápice da convergência de crises em escala global nos anos de 2008/2008, o Paraguai tem experimentado diferentes e intensos processos econômicos, políticos e sociais, relacionados sobretudo com a expansão do agronegócio, que resultam em diferentes transformações agrárias, orientadas para a transnacionalização definitiva do território.

Na pesquisa de doutorado ainda em desenvolvimento levantamos o total temos 53 empresas do agronegócio estrangeiro territorializadas no Paraguai, sendo que 19 são de origem brasileira, atuantes principalmente na produção de soja. No caso de empresas nacionais com presença de capital internacional há a 23 empresas, sendo de 18 são constituídas pelo capital brasileiro. Sobre estes dados há três ressalvas: 1) há grandes produtores que não constituíram empresas no Paraguai, especialmente no que se corresponde ao capital brasileiro, mas que do mesmo modo desenvolve uma função essencial na cadeia produtiva da soja, inclusive estão frequentemente envolvidos em conflitos, visto que estes produtores individuais expandem seus territórios através da apropriação ilegal de terras de reforma agrária, desterritorializando camponeses; 2) há um significativo número de colônias menonitas no país, que corresponde a um grupo religioso fechado oriundo da Rússia, Alemanha e Canadá, territorializadas especialmente no Chaco e, em menor proporção, nos departamentos de Itapúa, San Pedro e Caaguazú, resultado de uma política de migração e colonização impulsionada pelo Estado paraguaio desde a década de 1920 (VÁZQUEZ, 2013); 3) evidente que na realidade o número de empresas estrangeiras dedicadas ao agronegócio é bem maior, contudo não há dados, especialmente em âmbito governamental sobre as mesmas, não há um controle do Estado sobre o processo, no qual Barbanti Jr (2017) argumenta que há um descontrole intencional. Estas empresas identificadas durante a pesquisa equivalem àquelas que exercem maior controle do território e que estão envolvidas em conflitos.

O Estado possuí um papel elementar neste processo. De acordo com Wolford, Borras Jr, Hall, Scoones e White (2013), o Estado é um agente chave e contraditório na estrangeirização da terra, ou seja, facilita investimentos ao mesmo tempo em que cria barreiras. Contudo, o Estado paraguaio atua totalmente para a consolidação da estrangeirização do território, visto que 
suas políticas públicas e ações são para atender a demanda do capital externo e criminalizar a população camponesa. O Estado paraguaio legitima as ações, muitas vezes ilegais, de empresas estrangeiras colocando em xeque a soberania economia, política, alimentar e territorial do país.

\section{CONSIDERAÇõES FINAIS}

O Paraguai é um caso particular no que se refere a estrangeirização da terra, pois há muito tempo experimenta processos abordados como exclusivos do século XXI pela academia internacional. A estrangeirização do território no Paraguai remonta a Guerra da Tríplice Aliança (1864-1870) e desde então tem avançado através de mecanismos e estratégias cada vez mais sofisticadas, que permitem o controle - direto e indireto - do território pelo capital estrangeiro. Com o final da Grande Guerra a principal área de interesse foi o Chaco paraguaio, no qual empresas argentinas e inglesas exerceram hegemonia no controle do território. Na década de 1950 há uma reorientação dos investimentos em terras para a região Oriental, resultado em parte dos processos nos quais passavam o Brasil. No século XXI, há a consolidação do agronegócio estrangeiro na região Oriental e expansão da fronteira agrícola novamente em direção ao Chaco, inserindo nesta dinâmica novos agentes, como as imobiliárias uruguaias, tornando mais complexa a questão agrária paraguaia.

Segundo a GRAIN (2016), a estrangeirização da terra em escala global começou a avançar em 2008 e em 2012 diminuiu o ritmo, embora continue em expansão. Porém no Paraguai o ápice foi após o ano 2012, isto porque de entre 2008 e 2012 o Paraguai era governado por Fernando Lugo (Partido Frente Guasú), caracterizado por ser pós-neoliberal (SADER, 2009), isto é, incentiva a pequena e média empresa, a produção de alimentos, apoio a reforma agrária e movimentos socioterritoriais, porém ao mesmo tempo atende as demandas da classe empresarial e latifundista, ou seja, não rompe com as estruturas do capitalismo neoliberal. Mas a partir do momento em que Lugo começou a intervir em questões que são os pilares do modelo acumulação paraguaio, como a sua postura de realizar mensuras judiciais em propriedades de Tranquilo Favero, produtor de soja brasileiro em Nacunday (Alto Paraná), foi deposto através de um golpe parlamentar. Isto evidencia o poder do agronegócio no Paraguai.

Com a deposição de Lugo em junho de 2012 o liberal Federico Franco (Partido Liberal) assume a presidência do país e em 2013 o Partido Colorado retorna ao poder com a eleição de Horacio Cartes. A partir deste momento a estrangeirização do território paraguaio se acentua, onde o Estado promoveu e continua promovendo toda uma estrutura que permite este avanço, como por exemplo uma política massiva de atração de investimentos externos, na qual Cartes utiliza a seguinte propaganda: "El Paraguay debe ser como una mujer bonita, fácil y barata" (Entrevista realizada com Perla Álvarez ${ }^{15}$, em dezembro de 2015). Além disso há promulgação de leis que criminalizam movimentos de luta pelo território, como o Decreto n. 103, de 24 de agosto de 2013 que autoriza ação das forças armadas nos departamentos de Amambay, Concepción e San Pedro, caracterizando a luta pela terra como atividade terrorista, dentre outras dezenas de ações governamentais.

Neste cenário a tendência é a consolidação de um modelo agroextrativista, isto é, agricultura orientada para o monocultivo, geralmente com alto grau de tecnificação, mas com pouco ou nenhum processamento e com destino a exportação (GUDYNAS, 2010), um modelo para atender os interesses do mercado internacional. Assim, a projeção é o aumento da concentração fundiária e de renda, desterritorialização de camponeses e indígenas, crescimento sem planejamento de centros urbanos, acentuação da pobreza, criminalização dos movimentos socioterritoriais, diminuição da produção de alimentos - com consequente aumento da insegurança alimentar e perda da soberania alimentar - e aumento dos impactos ambientais. Todos estes impactos elencados já compõem a realidade paraguaia e com o governo de Mario Abdo Benítez, também do Partido Colorado, que se iniciará em agosto de 2018, a tendência é a manutenção de um modelo que concentra a terra em posse daqueles que, frequentemente, se apropriam do território de forma ilegal e que criminalizam aqueles que lutam de forma digna pelo acesso a um pedaço de terra para a sua reprodução. Ou seja, como já destacou Mondragón (2007): é tudo para o capital transnacional.

\section{REFERÊNCIAS}

ADNAN, S. Land grabs and primitive accumulation in deltaic Bangladesh: interactions between neoliberal globalization, state interventions, power relations and peasant resistance. The Journal of Peasant Studies, v. 40, n. 01, p. 87-128, 2013. ${ }^{15}$ Perla Álvarez é uma das dirigentes da Coordinadora de Mujeres Rurales e Indígenas (CONAMURI), movimento
socioterritorial paraguaio que atua, sobretudo, na luta pela soberania alimentar. Perla autorizou a divulgação do seu nome. 
AKRAM-LODHI, A. H. Contextualizing land grabbing: contemporary land deals, the global subsistence crisis and the world food system. Canadian Journal of Development Studies, n. 33, v. 2, p. 199-142, 2012.

ALBUQUERQUE, J. L. C. A dinâmica das fronteiras: os brasiguaios na fronteira entre o Brasil e o Paraguai. São Paulo: Editora Annablume, 2010.

ALONSO-FRADEJAS, A. Anything but a story foretold: multiple politics of resistance to the agrarian extractivist project in Guatemala. The Journal of Peasant Studies, v. 42, n. 3-4, p. 489-515, 2015.

ARRIGHI, G. Adam Smith em Pequim: as origens e fundamentos do século XXI. Rio de Janeiro: Boitempo, 2008.

BANCO MUNDIAL. Rising Global Interest in Farmland: Can it yield sustainable and equitable benefits?. Washington D.C.: The World Bank, 2011.

BARBANTI JR, O. Internacionalização de terras no Brasil: perspectivas para o setor de plantações de madeira. Estudos Internacionais, v. 5, n.2, p. $132-154,2017 b$

BARRETO, M. Tierras Malhabidas. Asunción: CSER, 2006.

BOFILL, I. E. I. La soja en Paraguay: concentración, extranjerización de la tierra y las consecuencias en el campesinado.

Madrid, 2012. 94 f. Dissertação (Mestrado em Estudios Contemporáneos de América Latina). Facultat de Ciencias Políticas y Sociología, Universidad Complutense de Madrid, Madrid (Espanha), 2012.

BORRAS JR, S.; KAY, C.; GÓMEZ, S.; WILKINSON, J.n. Land grabbing and global capitalism accumulation: key features in Latin America. Canadian Journal of Development Studies, v. 33, n. 04, p. 402-416, 2012.

BORRAS JR., Saturnino; FRANCO, Jennifer. Global land grabbing and political reactions "From Below". Third World Quarterly Journal, v. 34, n. 9, p. 1.723-1.747, 2013.
BUSCIOLI, L.D. Impactos e resistências no processo de estrangeirização de terras em Rio Brilhante (MS): o caso dos projetos de assentamentos federais São Judas Margarida Alves, Silvio Rodrigues e do Território Indígena Laranjeira Ñanderu. Presidente Prudente, 2016, 454 f. Dissertação (Mestrado em Geografia) - Faculdade de Ciências e Tecnologia, Universidade Estadual Paulista "Júlio de Mesquita Filho", Presidente Prudente, 2016.

CABALlero, G. D. C. El árbol de quebracho y la Guerra del Chaco. Revista Paraguaya de Sociología, ano 51, n. 146, p. 191-204, 2014.

CAPECO. Cámara Paraguaya de Exportadores y Comercializadores de Cereales y Oleaginosas. Disponível em: http://capeco.org.py/. Acesso em: 25 mai. 2018.

CUNHA, J. S. Governo Temer: Relações do agronegócio com o capital especulativo financeiro e impactos sobre os camponeses e a legislação agrária. Cadernos do Centro de Estudos e Ação Social (CEAS), n. 241, p. 301-326, 2017

DANIEL, Shepard. Situating private equity capital in the land grabbing debate. The Journal of Peasant Studies, v. 39, n. 3-4, p. 703-729, 2012.

DESMARAIS, A. A.; QUALMAN, D.; MAGNAN, A.; WIEBE, N. ¿Propiedad agrícola para los inversionistas o las inversiones sociales? La transformación de la propiedad de la tierra en Saskatchewan, Canadá. Revista NERA, ano 20, n. 40, p. 181-205, 2017.

EDELMAN, M.; OYA, C.; BORRAS JR., S. Global land grabs: historical processes, theoretical and methodological implications and current trajectories. Third World Quarterly, v. 34, n. 9, p. 1517-1531, 2013.

EDELMAN, M. Estudios agrarios críticos: tierras, semillas, soberanía alimentaria y derechos de las y los campesinos. Quito: Editorial IAEN, 2016.

FOGEL, R. Las luchas campesinas: tierra y condiciones de producción. Asunción: CERI, 2001. 
FAIRBAIRN, M. Like gold with yield': evolving intersections between farmland and finance. The Journal of Peasant Studies, v. 41, n. 5, p. 777 $795,2014$.

Foreignization, financialization and land grab regulation. Journal of Agrarian Change, v. 15, n. 4, p. 581-591, 2015.

FAIRHEAD, J.; LEACH, M.; SCOONES, Ian. Green Grabbing: a new appropriation of nature? The Journal of Peasant Studies, v. 39, n. 2, p. 237-261, 2012.

FREDERICO, S. Território, capital financeiro e agricultura. (Relatório de pesquisa). São Paulo: FAPESP, 2015.

GALEANO, L. (Org.). Procesos agrarios y democracia en Paraguay y América Latina. Asunción: CPES, 1990.

La nueva ruralidad: transformaciones y desafíos del Paraguay rural contemporáneo. BRUN, Diego Abente; BORDA, Dionisio (Org.). El reto del futuro. Asumiendo el legado del bicentenario. Asunción: Ministerio de Hacienda, p. 155-190, 2011.

GINGEMBRE, M. Resistance or participation fighting against corporate land access amid political uncertainty in Madagascar. The Journal of Peasant Studies, v. 42, n. 3-4, p. 561-584, 2015.

GLAUSER, M. Extranjerización del territorio paraguayo. Asunción: BASE Investigaciones Sociales, 2009.

GRAIN. El acaparamiento global de tierras en el 2016 - sigue creciendo y sigue siendo malo. Barcelona: GRAIN, 2016.

HETHERINGTON, K. Tierra malhabida y el engaño de la institucionalidad. Revista de Estudios Políticos Contemporáneos (NOVAPOLIS), n. 5, p. 31-54, 2012.

HOBSBAWN, E. A Era dos Impérios (1875-1914). São Paulo: Paz e
Terra, 1988

HOLMES, G. What is land grabbing? Exploring green grabs, conservation and private protected areas in Southern Chile. The Journal of Peasant Studies, v. 41, n. 4, p. 547-567, 2014.

INCE, O.U. Primitive accumulation, new enclosures, and global land grabs: a theoretical intervention. Rural Sociology, v. 79, n. 1, p. 104-131, 2013.

KINUTHIA, W. 'Accumulation by dispossession' by the global extractivism industry: the case of Canada. Dessertação (master degree in Globalization and International Development), School of International Development and Global Studies, Faculty of Social Science, University of Ottawa, 2013

KLEINPENNING, J. Rural development policy in Paraguay since 1960. Tijdschrift voor Econ. en Soc. Geografie, v. 75, n. 3, p. 164-176, 1984.

Paraguay Rural (1870-1963): una Geografía del progreso, el pillaje y la pobreza. Asunción: Editorial Tiempo de Historia, 2014.

LANDÍVAR, N. ; LLAMBÍ, L. Tierras, territorios y procesos territoriales: Planteamientos teóricos y análisis de los procesos de acaparamiento de tierras y territorios en Ecuador con posterioridad al 2008. Campo-Território, Ed. Especial Land Grabbing, Grilagem e Estrangeirização de terras, n. 23, v. 11, p. 76-115, 2016

MAG. Censo Agropecuario Nacional 1981. Asunción: Ministerio de Agricultura y Ganadería, 1981.

MAG. Censo Agropecuario Nacional 1991. Asunción: Ministerio de Agricultura y Ganadería, 1991.

MAG. Censo Agropecuario Nacional 2008. Asunción: Ministerio de Agricultura y Ganadería, 2008.

MAG. Síntesis estadísticas - producción agropecuaria año agrícola 
2016/2017. Asunción: Ministerio de Agricultura y Ganadería, 2018.

McKAY, B. Control grabbing and value-chain agriculture: BRICS, MICS and Bolivia's soy complex. Globalizations, v.14, n. 5, p. 01-18, 2017.

MONDRAGÓN. H. La estrategia del imperio. Todo para el capital transnacional. Bogotá: Ántropos, 2007.

MORA, C. Participación y organizaciones campesinas en Paraguay. GRAMMONT, Hubert C. (Org.). Construcción de la democracia en el campo latinoamericano. Buenos Aires: CLACSO, p. 343-365, 2006.

MORAES, I. A.; VIEIRA, F. A. C. Capitalismo agrário e movimentos campesinos no Paraguai. Revista Estudos Históricos, v. 28, n, 56, p. 363$384,2015$.

MOREDA, T. Listening to their silence? The political reaction of affected communities to large-scale land acquisitions: insights from Ethiopia. The Journal of Peasant Studies, v.42, n. 3-4, p. 517-539, 2015.

MORÍNGO, J. N. De la protesta social al movimiento campesino. Revista de Estudios Políticos Contemporáneos (NOVAPOLIS), n. 2, p. 24-31, 2003.

MOTA, C. G. História de um silêncio: a guerra contra o Paraguai (18641870) 130 anos depois. Estudos Avançados, v. 9, n. 24, 1995.

NALEPA, R. A question of scale: the construction of marginal lands and the limitation of global land classifications. International Conference on Global Land Grabbing, University of Sussex, Brighton, 2011.

OYA, C. Methodological reflections on "land grab" databases and the "land grab" literature "rush". The Journal of Peasant Studies, v. 40, n. 3, p. 503-520, 2013a.

OYA, C. The land rush and classic agrarian questions of capital and labour: a systematic impact of land grabs in Africa. Third World Quarterly, v. 34, n. 9, p. 1532-1557, 2013b.
PALAU, T.; HEIKEL, M.V. Los campesinos, el Estado y las empresas en la frontera agrícola. Asunción: BASE Investigaciones Sociales, 1987.

PALAU, T. El Agronegocio de la soja en Paraguay - Antecedentes e impactos sociales y económicos. FERNANDES, Bernardo Mançano (Org.). Campesinato e agronegócio na América Latina: a questão agrária atual. São Paulo: Expressão Popular, 2008.

PASTORE, C. La lucha por la tierra en Paraguay. Asunción: Intercontinental Editora, 2015 (1972).

PEDLOWSKI, M. A. When the state becomes the land grabber: evidence and dispossession in the name of 'development' in Brazil. Journal of Latin American Geography, v. 12, n. 3, p. 91-111, 2013.

PEREIRA, L. I. Controle de terras no Paraguai: um estudo através da apropriação do território por empresas argentinas, brasileiras e uruguaias. XII Encontro Nacional da ANPEGE "Geografia, Ciência e Política: do pensamento à ação, da ação ao pensamento". Anais...: Porto Alegre, p. 13.705-13.716, 2017.

PLOEG, J.B. V.; FRANCO, J.; BORRAS JR., S.. Land concentration and land grabbing in Europe: a preliminary analysis. Canadian Journal of Development Studies, v. 36, n. 02, p. 147-162, 2015.

REVISTA VEJA. Os brasileiros no Paraguai. Revista Veja, Caderno Especial, p. 46 a 54, 24 set. 1975.

RIQUELME, M. Notas para el estudio de las cusas y efectos de las migraciones brasileñas en el Paraguay. FOGEL, Ramón; RIQUELME, Marcial (Org.). Enclave sojero, merma de la soberanía y pobreza. Asunción: CERI, p. 113-147, 2005.

RIQUELME, Q. Los sin tierra en Paraguay. Conflictos agrarios y movimiento campesino. Buenos Aires: CLACSO, 2003.

RIQUELME, Q.; KRETSCHMER, R. Concentración de tierras y producción en Paraguay. Análisis comparativo de los censos agropecuarios 
de 1991-2008. Asunción: CDE, 2016.

SADER, E. A nova toupeira: os caminhos da esquerda latino-americana. São Paulo: Boitempo, 2009.

SASSEN, S. A savage sorting of winners and losers: contemporary versions of primitive accumulation. Globalizations, v. 7, n. 1, p. 23-50, 2010.

Lands grabs today: feeding the disassembling of national territory. Globalizations, v. 10, n. 1, p. 25-46, 2013.

Expulsões - Brutalidade e complexidade na economia global. Rio de Janeiro/São Paulo: Paz \&Terra, 2016.

SAUER, S.; BORRAS JR, S. 'Land Grabbing' e 'Green Grabbing': uma leitura da 'corrida na produção acadêmica' sobre a apropriação global de terras. Revista Campo-Território, Ed. Especial Land Grabbing, Grilagem e Estrangeirização de terras, n. 23, v. 11, p. 06-42, 2016.

TIERRAS MALHABIDAS. Tierras Malhabidas: las estamos pagando. Disponível em: http://www.tierrasmalhabidas.com.py/. Acesso em: 23 mai. 2018.

VÁZQUEZ, F. Territorio y población: nuevas dinámicas regionales en el Paraguay. Asunción: ADEPO, 2006.

Geografía humana del Chaco Paraguayo. Transformaciones territoriales y desarrollo regional. Asunción: ADEPO, 2013.

VILlAGRA, L. R. Actores del Agronegocio en Paraguay. Asunción: BASE Investigaciones Sociales, 2009.

Proceso histórico de la economía paraguaya. Asunción: Secretaría Nacional de Cultura, 2012.

La metamorfosis del Paraguay. Del esplendor inicial a su traumática descomposición. Asunción: BASE Investigaciones Sociales, 2014.

VISSER, O. Finance and the global land rush: understanding the growing role of investment funds in land deals and large-scale farming. Canadian Food Studies, v. 2, n. 2, p. 278-286, 2015.

WILKINSON, J. Land grabbing e estrangeirização da terra no Brasil. MALUF, Renato S.; FLEXOR, Georges (Org.). Questões agrárias, agrícolas e rurais. Conjunturas e políticas públicas. Rio de Janeiro: E-papers, p. 39-51, 2017.

WILY, L. A. Looking back to see forward: the legal niceties of land theft in land rushes. The Journal of Peasant Studies, v. 39, n.03-04, p. 751-775, 2012.

WOLFORD, W.; BORRAS JR., S.; HALL, R.; SCOONES, I.; WHITE, Ben. Governing global land deals: the role of State in the rush for land. Development and Change, v. 44, n. 2, p. 189-210, 2013.

YEGROS, R.; BREZZO, L. História das Relações Internacionais do Paraguai. Brasília: Fundação Alexandre de Gusmão, 2013. 